\title{
Television viewing and obesity among Iranian children: the importance of economic status and residential area
}

\author{
${ }^{*}$ Gholamreza Veghari ${ }^{1}$ \\ Sri Lanka Journal of Child Health, 2015; 44(3): 147-152
}

\begin{abstract}
Background: Obesity is a health problem among adolescents worldwide and television (TV) viewing could promote it in several ways.
\end{abstract}

Objective: To determine the association between time spent on TV viewing and obesity considering economic status and residential area in primary schoolchildren in the north of Iran.

Method: A descriptive cross-sectional study was carried out on primary schoolchildren from 112 schools. Schools and students were chosen by cluster sampling. All children completed a questionnaire containing questions on the socio-economic condition. Overweight and obesity were classified based on the Centres for Disease Control and Prevention (CDC) values with body mass index (BMI) in excess of the 85th and 95th percentiles, respectively. Daily time spent on TV viewing was classified into 3 groups: less than 1 hour or no watching, 1-2 hours and 3 hours or over. SPSS 16.0 software was used for statistical data analysis.

Results: Study population comprised 7,453 primary schoolchildren (urban 3,662, rural 3,791). Of the subjects $52.7 \%$ viewed TV for 3 hours or more. In boys, prevalence of obesity had a positive association with TV viewing time but in girls, it was not a steady trend. In urban areas, time spent on TV viewing was in line with obesity but wasting significantly decreased with more time spent on TV viewing $(\mathrm{P}=0.001)$. This association was not seen in rural children. In the poor economic group, prevalence of obesity significantly decreased with more time spent on TV viewing $(\mathrm{P}=0.041)$ but this trend was not found in the moderate economic group. In the good economic group, the association between obesity and time spent on the TV viewing was not significant.

${ }^{1}$ Assistant Professor of Nutrition, Ischaemic
Disorders Research Centre, Golestan University of
Medical Sciences, Gorgan, Iran
${ }^{*}$ Correspondence: grveghari@yahoo.com

(Received on 23 August 2014: Accepted after revision on 24 October 2014)
Conclusion: About half of Iranian northern schoolchildren spent 3 hours or more daily viewing $\mathrm{TV}$. A positive association between time spent on TV viewing and obesity was seen in high income families and in urban areas.

(Keywords: Obesity, television, schoolchildren, socioeconomic status, Iran)

\section{Introduction}

Obesity has doubled during the past two decades in Iran ${ }^{1}$. Many cross-sectional studies, but not all, have identified a positive association between time spent on TV viewing and the weight status of children ${ }^{2,3}$. Reducing sedentary behaviour, including TV viewing, is important in prevention of overweight and obesity ${ }^{4,5}$. Children who watched over 5 hours of TV were 4.6 times as likely to be overweight as children who watched $0-1$ hours per $d^{2} y^{6}$. Findings from longitudinal studies also showed that children who watched more TV have more overweight, even after 6 or 11 years of follow-up assessment ${ }^{7}$. In a randomized trial among elementary schoolchildren, obesity declined when time spent on TV viewing was reduced after 1 year ${ }^{8}$. TV viewing could promote obesity by promoting poor diets, displacing time for physical activity, giving more opportunities for unhealthy snacking and by interfering with sleep ${ }^{9,10}$. Golestan province is located north of Iran and 1.7 million people (56\% urban, $44 \%$ rural) live in this area where the main job is agriculture ${ }^{11}$.

\section{Objective}

Main aim of this study is to determine the association between time spent on TV viewing and obesity considering the economic status and residential area in primary schoolchildren north of Iran.

\section{Method}

A cross-sectional retrospective study was carried out in children from 112 schools north of Iran. Schools and students were chosen by cluster sampling. Golestan province has 14 districts and initially, all primary schools in each district were numbered. Then 8 schools were randomly chosen from each district 
Television viewing and obesity among Iranian children: the importance of economic status and residential area Sri Lanka Journal of Child Health, 2015; 44(3): 147-152

by school list. After enrolling 112 schools, a systematic random sample of students was drawn from each school using the student class list. From each class, 15 subjects were chosen by systematic random sampling and in villages with less than 15 students, all were chosen. Date of birth was obtained from school file. Of total sample, 34 students $(0.5 \%)$ were excluded because some data was missing.

The estimated sample size was based on stratification of respondents by urban/rural and gender of 14 district areas. With resumption of $50 \%$ prevalence rate, a confidence level of $95 \%$ and a maximum marginal error about 0.02 , the sample size was calculated to be 2401 subjects. With regard to cluster sampling methods, sample size enlarged up to three times the baseline sample size. Gender, age, location area, economic status, weight, height and TV viewing time were recorded by questionnaire. Overweight and obesity were classified based on the Centres for Disease Control and Prevention (CDC) values with body mass index (BMI) in excess of the 85th and 95 th percentiles, respectively ${ }^{8}$.

Economic status was categorized based on possession of 10 consumer items considered necessary for modern-day life viz. telephone, running water, gas pipeline, home ownership, colour television, computer, video, modern refrigerator, private car and cooler. According to this list, the economic status of participants was categorized as follows: 3 or less as low, 4-6 as moderate and 7-10 as good. Daily time spent on TV viewing was classified into three groups: less than 1 hour or no watching, 1-2 hours and 3 hours or more. Anthropometric measurements of the children were performed in light dress and without shoes in the morning. Body-weight was measured to the nearest $0.1 \mathrm{~kg}$ using a balanced-beam scale, and height was measured to the nearest $0.5 \mathrm{~cm}$ with the child standing up and head, back, and buttock on the vertical land of the height-gauge.
SPSS 16.0 software was used for statistical data analysis. Chi-square test was used for qualities groups and P-value under 0.05 indicated significance. This study was approved by Ethical Research Committee of Golestan University of Medical Sciences. Verbal informed consent was received from parents of all the children.

\section{Results}

The study population comprised 7,453 primary schoolchildren. The baseline characteristics of the study population are shown in Table 1 .

Table 1

Baseline characteristics of study population $(n=7453)$

\begin{tabular}{|l|c|}
\hline \multicolumn{1}{|c|}{ Variable } & Number (\%) \\
\hline Region & $3662(49.1)$ \\
Urban & $3791(50.9)$ \\
Rural & $3963(53.2)$ \\
\hline Gender & $3490(46.8)$ \\
Male & \\
Female & $600(15.1)$ \\
\hline Obesity & $442(12.7)$ \\
Male & \\
Female & $1172(15.8)$ \\
\hline Economic status & $4523(61.0)$ \\
Low & $1724(23.2)$ \\
Moderate & \\
Good & $902(12.1)$ \\
\hline TV viewing time & $2624(35.2)$ \\
$<1$ hour or no watching & $3927(52.7)$ \\
1-2 hours & \\
3 hours or more & \\
\hline
\end{tabular}

*34 cases no response to this question

Distribution of obesity based on sex and time spent on TV viewing is shown in table 2.

Table 2: Distribution of BMI based on gender and time spent on the TV viewing

\begin{tabular}{|l|l|c|c|c|c|}
\hline \multirow{3}{*}{ Gender } & \multicolumn{1}{|c|}{ TV viewing time } & \multicolumn{4}{|c|}{ BMI Distribution Number (\%) } \\
\cline { 3 - 6 } & & $<5 \%$ BMI-CDC & $5-85 \%$ BMI-CDC & $85-95 \%$ BMI-CDC & $\geq 95 \%$ BMI-CDC \\
\hline \multirow{5}{*}{ Male } & $<$ hour or no viewing (404) & $124(30.7)$ & $198(49.0)$ & $26(6.4)$ & $56(13.9)$ \\
\cline { 2 - 6 } & $1-2$ hours (1281) & $329(25.7)$ & $662(51.7)$ & $102(8.0)$ & $188(14.7)$ \\
\cline { 2 - 6 } & 3 hours or over (2278) & $518(22.7)$ & $1191(52.3)$ & $213(9.4)$ & $356(15.6)$ \\
\cline { 2 - 6 } & Total (3963) & $971(24.5)$ & $2051(51.8)$ & $341(8.6)$ & $600(15.1)$ \\
\cline { 2 - 6 } & P value & 0.001 & 0.477 & 0.369 & 0.562 \\
\hline \multirow{5}{*}{ Female } & $<$ hr or no viewing (498) & $129(25.9)$ & $263(52.8)$ & $49(9.8)$ & $57(11.5)$ \\
\cline { 2 - 6 } & $1-2$ hours (1343) & $313(23.3)$ & $741(55.2)$ & $112(8.3)$ & $177(13.2)$ \\
\cline { 2 - 6 } & 3 hours or over (1649) & $442(26.8)$ & $878(53.2)$ & $121(7.3)$ & $208(12.6)$ \\
\cline { 2 - 6 } & Total (3490) & $884(25.3)$ & $1882(53.9)$ & $282(8.1)$ & $442(12.7)$ \\
\cline { 2 - 6 } & P value & 0.086 & 0.496 & 0.180 & 0.608 \\
\hline
\end{tabular}


Television viewing and obesity among Iranian children: the importance of economic status and residential area Sri Lanka Journal of Child Health, 2015; 44(3): 147-152

In boys, prevalence of obesity had a positive association with TV viewing time but statistical difference was not significant and wasting rate $(<5 \%$ BMI-CDC) significantly decreased with more
TV viewing time $(\mathrm{P}=0.001)$. In girls, obesity and time spent on TV viewing was not a steady correlation. Distribution of obesity based on location and time spent on TV viewing is shown in table 3.

Table 3: Distribution of BMI based on location area and time spent on the TV viewing

\begin{tabular}{|l|l|c|c|c|c|}
\hline \multirow{2}{*}{ Location } & \multicolumn{1}{|c|}{ TV viewing time } & \multicolumn{4}{|c|}{ BMI distribution } \\
\cline { 3 - 6 } & & $<5 \%$ BMI-CDC & $5-85 \%$ BMI-CDC & $85-95 \%$ BMI-CDC & $>=95 \%$ BMI-CDC \\
\hline \multirow{4}{*}{ Urban } & $<$ hour or no viewing (389) & $123(31.6)$ & $183(47.1)$ & $28(7.2)$ & $55(14.1)$ \\
\cline { 2 - 6 } & $1-2$ hours (1269) & $316(24.9)$ & $643(50.7)$ & $110(8.7)$ & $200(15.8)$ \\
\cline { 2 - 6 } & 3 hours or over (2004) & $460(23.0)$ & $1012(50.4)$ & $172(8.6)$ & $360(18.0)$ \\
\cline { 2 - 6 } & Total (3662) & $899(24.5)$ & $1838(50.2)$ & $310(8.5)$ & $615(16.8)$ \\
\cline { 2 - 6 } & P value & 0.001 & 0.420 & 0.636 & 0.086 \\
\hline \multirow{5}{*}{ Rural } & $<1$ hour or no viewing (513) & $130(25.3)$ & $278(54.2)$ & $47(9.2)$ & $58(11.3)$ \\
\cline { 2 - 6 } & 1-2 hours (1355) & $326(24.1)$ & $760(56.1)$ & $104(7.7)$ & $165(12.2)$ \\
\cline { 2 - 6 } & 3 hours or over (1923) & $500(26.0)$ & $1057(55.0)$ & $162(8.4)$ & $204(10.4)$ \\
\cline { 2 - 6 } & Total (3791) & $956(25.2)$ & $2095(55.3)$ & $313(8.3)$ & $427(11.3)$ \\
\cline { 2 - 6 } & P value & 0.450 & 0.711 & 0.540 & 0.375 \\
\hline
\end{tabular}

In urban children, time spent on TV viewing was associated with obesity but wasting rate $(<5 \%$ BMI$\mathrm{CDC})$ significantly decreased with more time spent on $\mathrm{TV}$ viewing $(\mathrm{P}=0.001)$. The association between time spent on the TV viewing and obesity was not seen in rural areas. Distribution of obesity based on economic status and time spent on TV viewing is shown in table 4.

Table 4: Distribution of BMI based on economic status and time spent on TV viewing

\begin{tabular}{|c|c|c|c|c|c|}
\hline \multirow{2}{*}{$\begin{array}{c}\text { Economic } \\
\text { status }\end{array}$} & \multirow[t]{2}{*}{$T V$ viewing time } & \multicolumn{4}{|c|}{ BMI distribution Number (\%) } \\
\hline & & $<5 \%$ BMI-CDC & 5-85\%BMI-CDC & $85-95 \%$ BMI-CDC & $>=95 \%$ BMI-CDC \\
\hline \multirow[t]{5}{*}{ Poor } & $<1 \mathrm{hr}$ or no viewing $(207)$ & $58(28.0)$ & $111(53.6)$ & $12(5.8)$ & $26(12.6)$ \\
\hline & 1-2 hours (435) & $126(29.0)$ & $237(54.5)$ & $28(6.4)$ & $44(10.1)$ \\
\hline & 3 hours or over $(530)$ & $156(29.4)$ & $297(56.0)$ & $40(7.6)$ & $37(7.0)$ \\
\hline & Total (1172) & $340(29.0)$ & $645(55.0)$ & $80(6.8)$ & $107(9.1)$ \\
\hline & $\mathrm{P}$ value & 0.929 & 0.804 & 0.643 & 0.041 \\
\hline \multirow[t]{5}{*}{ Intermediate } & $<1 \mathrm{hr}$ or no viewing $(545)$ & $161(34.8)$ & $281(10.3)$ & $47(8.6)$ & $56(10.3)$ \\
\hline & $1-2$ hours $(1625)$ & $408(25.1)$ & $889(54.7)$ & $127(7.8)$ & $201(12.4)$ \\
\hline & 3 hours or over $(2352)$ & $584(24.8)$ & $1258(53.5)$ & $199(8.5)$ & $312(13.2)$ \\
\hline & Total $(4523)$ & $1153(25.5)$ & $2428(53.7)$ & $373(8.2)$ & $569(12.6)$ \\
\hline & P. Value & 0.068 & 0.425 & 0.724 & 0.157 \\
\hline \multirow[t]{5}{*}{ Good } & $<1 \mathrm{hr}$ or no viewing (141) & $33(23.4)$ & $65(46.1)$ & $14(9.9)$ & $29(20.6)$ \\
\hline & $1-2$ hours $(554)$ & $102(18.4)$ & $273(49.3)$ & $59(10.6)$ & $120(21.7)$ \\
\hline & 3 hours or over (1029) & $216(21.0)$ & $507(49.3)$ & $94(9.1)$ & $212(20.6)$ \\
\hline & Total (1724) & $351(20.4)$ & $845(49.0)$ & $167(9.7)$ & $361(20.9)$ \\
\hline & $P$ value & 0.307 & 0.770 & 0.620 & 0.879 \\
\hline
\end{tabular}

There was a positive and significant association between obesity and economic status levels $(\mathrm{P}=0.001)$. In poor economic group, prevalence of obesity significantly decreased with more time spent on $\mathrm{TV}$ viewing $(\mathrm{P}=0.041)$ but this trend was not seen in moderate economic group. In the good economic group, association between obesity and time spent on the TV viewing was not significant.

\section{Discussion}

Daily TV viewing time for 3 hours or over was seen in $52.7 \%$ of school children. In Tabriz, a capital city in northwest Iran, $37.5 \%$ and $13.7 \%$ of primary schoolgirls viewed TV for 2-4 hours and over 4 hours respectively $^{12}$. In Milan, $85.3 \%$ of primary schoolchildren watch TV from 30 minutes to 2 hours per day ${ }^{13}$. More time spent on TV viewing in our area may be related to lack of access to other amenities. In the present study, a steady trend was seen between TV viewing time and obesity in urban areas while this trend was not seen in rural areas. The association between obesity and time spent on the TV viewing was converse in poor economic children.

Some studies in children and teens suggest that computer, video game and internet use are associated with excess weight ${ }^{14-16}$ while other studies have not 
Television viewing and obesity among Iranian children: the importance of economic status and residential area Sri Lanka Journal of Child Health, 2015; 44(3): 147-152

found similar effects ${ }^{17-18}$. In Iranian adolescents, the time spent on TV viewing was associated with an increased risk of obesity while obesogenic foods and physical activity had no effect on the frequency of obesity $^{19}$. In Portugal, only $12.2 \%$ of children spend 1.5 hours or less on TV and computer and boys who spend less time on TV and computer were $75.4 \%$ less likely to be overweight/obese than those who spend more time ${ }^{20}$. Indicators of sedentary lifestyle, such as screen time and presence of a TV in the child's bedroom, were associated with overweight and obesity in Norwegian schoolchildren ${ }^{21}$. In a review study within 43 countries it was shown that physical activity levels were lower and TV viewing times higher in overweight compared to normal weight youth $^{22}$. Physical activity levels were lower and TV viewing times higher in overweight and obese than in normal-weight in Canadian youth ${ }^{23}$. It has been proposed that through viewing $\mathrm{TV}$, people spend less time on performing physical activity and increased consumption of obesogenic foods ${ }^{10}$. However, Ekelund found that viewing TV increases adiposity independent of physical activity ${ }^{24}$. Overweight is the result of genetic and environmental factors ${ }^{25}$ and the tripled increase of overweight in the last decades ${ }^{26}$ implies that environmental factors have more effect on BMI than genetic factors. The association between the time spent on viewing TV and obesity among schoolchildren north of Iran is different compared with other regions. These differences can be related to some environmental factors such as food behaviour, physical activity, ethnicity and genetic factors that were not evaluated in our study.

\section{Conclusions}

- Fifty three percent of northern Iranian schoolchildren spent 3 hours or more viewing TV.

- A positive association between time spent on TV viewing and obesity was seen in high income families and in urban areas.

We did not evaluate all factors associated with obesity and TV viewing time such as food intake, ethnicity, other sedentary equipments and parents' education. In addition, we did not provide a proper statistical test to consider the design effect caused by cluster sampling. These are our limiting study factors.

\section{Acknowledgments}

The author thanks the medical and administrative staff in the Education Organization of Golestan Province for their valuable assistance during field work and the Vice-Chancellor of Research and Technology of Golestan University of Medical Sciences for financial support for this study.

\section{References}

1. Mohammadpour-Ahranjani B, Rashidi A, Karandish M, Eshraghian MR, Kalantari N. Prevalence of overweight and obesity in adolescent Tehrani students, 2000-2001: an epidemic health problem. Public Health Nutrition 2004; 7:645-8. http://dx.doi.org/10.1079/PHN2003593 PMid: 15251055

2. Eisenmann JC, Bartee RT, Wang MQ. Physical activity, TV viewing, and weight in U.S. youth: 1999 Youth Risk Behavior Survey. Obesity Research 2002; 10:379-85. http://dx.doi.org/10.1038/oby.2002.52 PMid: 12006637

3. Vandewater E, Shim M, Caplovitz A. Linking obesity and activity level with children's television and video game use. Journal of Adolescence 2004; 27:71-85. http://dx.doi.org/10.1016/j.adolescence.2003 .10 .003

PMid: 15013261

4. Salmon J, Ball K, Crawford D, Telford A, Hume C, Jolley D, et al. Reducing sedentary behaviour and increasing physical activity among 10-year-old children: overview and process evaluation of the 'Switch-Play' intervention. Health Promotion International 2005; 20(1):7-17. http://dx.doi.org/10.1093/heapro/dah502 PMid: 15668218

5. Caballero B. Obesity prevention in children: opportunities and challenges. International Journal of Obesity and Related Metabolic Disorders 2004; 28(3S):S90-S95. http://dx.doi.org/10.1093/heapro/dah502 PMid: 15668218

6. Gortmaker SL, Must A, Sobol AM, Peterson K, Colditz GA, Dietz WH. Television viewing as a cause of increasing obesity among children in the United States, 19861990. Archives of Pediatric and Adolescent Medicine 1996; 150(4): 356-62.

http://dx.doi.org/10.1093/heapro/dah502 PMid: 15668218 
Television viewing and obesity among Iranian children: the importance of economic status and residential area Sri Lanka Journal of Child Health, 2015; 44(3): 147-152

7. Proctor $\mathrm{MH}$, Moore LL, Gao D, Cupples LA, Bradlee ML, Hood MY, et al. Television viewing and change in body fat from preschool to early adolescence: the Framingham Children's Study. International Journal of Obesity and Related Metabolic Disorders 2003; 27(7): 827-33. http://dx.doi.org/10.1038/sj.ijo.0802294 PMid: 12821969

8. Gortmaker SL, Peterson K, Wiecha J, Sobol AM, Dixit S, Fox MK,et al. Reducing obesity via a school-based interdisciplinary intervention among youth: planet health. Archives of Pediatric and Adolescent Medicine 1999; 153(4):409-18.

http://dx.doi.org/10.1001/archpedi.153.4.409 PMid: 10201726

9. Sonneville KR, Gortmaker SL. Total energy intake, adolescent discretionary behaviors and the energy gap. International Journal of Obesity (Lond) 2008; 32 (Suppl 6):S19-27.

http://dx.doi.org/10.1038/ijo.2008.203

PMid: 19079276

10. Robinson TN. Reducing children's television viewing to prevent obesity: a randomized controlled trial. Journal of the American Medical Association 1999; 282:1561-7.

http://dx.doi.org/10.1001/jama.282.16.1561

PMid: 10546696

11. Statistical Center of Iran. Population and Housing Census [Online]. 2012; Available from:

http://www.amar.org.ir/Portals/1/Iran/census -2.pdf

12. Seyedamini B, Moradi A, Malek A, et al. The role of watching TV. In obesity and behavioral problem in children. Iran Journal of Nursing 2010; 23(67):8-14.[Persian]

13. Bracale R, Milani L, Ferrara E, Balzaretti C, Valerio A, Russo V, et al. Childhood obesity, overweight and underweight: a study in primary schools in Milan. Eating and Weight Disorders. 2013; 18(2):183-91. http://dx.doi.org/10.1007/s40519-013-00369

PMid: 23760847 PMCid: PMC3664740
14. Berkey CS, Rockett HR, Colditz GA. Weight gain in older adolescent females: the internet, sleep, coffee, and alcohol. Journal of Pediatrics. 2008; 153:635-9.

15. Schneider M, Dunton GF, Cooper DM. Media use and obesity in adolescent females. Obesity (Silver Spring). 2007; 15:2328-35. http://dx.doi.org/10.1007/s40519-013-00369

PMid: 23760847 PMCid: PMC3664740

16. Carvalhal MM, Padez MC, Moreira PA, Rosado VM. Overweight and obesity related to activities in Portuguese children, 7-9 years. European Journal of Public Health 2007; 17:42-6.

http://dx.doi.org/10.1093/eurpub/ck1093

PMid: 16793838

17. Swinburn B, Shelly A. Effects of TV time and other sedentary pursuits. International Journal of Obesity (Lond) 2008; 32 (Suppl 7):S132-6. http://dx.doi.org/10.1038/ijo.2008.249 PMid: 19136983

18. Rey-Lopez JP, Vicente-Rodriguez G, Biosca $\mathrm{M}$, Moreno LA. Sedentary behavior and obesity development in children and adolescents. Nutrition Metabolism and Cardiovascular Diseases 2008; 18:242-51. http://dx.doi.org/10.1016/j.numecd.2007.07. 008

PMid: 18083016

19. Ghavamzadeh S, Khalkhali HR, Alizadeh M. TV viewing, independent of physical activity and obesogenic foods, increases overweight and obesity in adolescents. Journal of Health Population and Nutrition 2013; 31(3):334-42.

http://dx.doi.org/10.3329/jhpn.v31i3.16825

PMid: 24288947 PMCid: PMC3805883

20. Vasques C, Mota M, Correia T, Lopes V. Prevalence of overweight/obesity and its association with sedentary behavior in children. Rev Port Cardiol. 2012; 31(12):783-8. http://dx.doi.org/10.1016/j.repce.2012.11.00 9 
21. Kristiansen $H$, Júlíusson PB, Eide GE, Roelants M, Bjerknes R. TV viewing and obesity among Norwegian children: the importance of parental education. Acta Paediatrica 2013; 102(2):199-205. http://dx.doi.org/10.1111/apa.12066

PMid: 23121043

22. Janssen I, Katzmarzyk PT, Boyce WF, Vereecken C, Mulvihill C, Roberts C, et al. Health behaviour in school-aged children Obesity Working Group. Comparison of overweight and obesity prevalence in school-aged youth from 34 countries and their relationships with physical activity and dietary patterns. Obesity Reviews 2005; 6(2):123-32.

http://dx.doi.org/10.1111/j.1467789X.2005. 00176.x

PMid: 15836463

23. Janssen I, Katzmarzyk PT, Boyce WF, King MA, Pickett W. Overweight and obesity in Canadian adolescents and their associations with dietary habits and physical activity patterns. Journal of Adolescent Health 2004; 35(5):360-7.

http://dx.doi.org/10.1016/j.jadohealth.2003.1 1.095
24. Ekelund U, Brage S, Froberg K, Harro M, Anderssen SA, Sardinha LB et al. TV viewing and physical activity are independently associated with metabolic risk in children: the European Youth Heart Study. PLoS Medicine 2006; 3:2449-57. http://dx.doi.org/10.1371/journal.pmed.0030 488

PMid: 17194189 PMCid: PMC1705825

25. Jacobson KC, Rowe DC. Genetic and shared environmental influences on adolescent BMI: interactions with race and sex. Behavior Genetics 1998; 28:265-78. http://dx.doi.org/10.1371/journal.pmed.0030 488

PMid: 17194189 PMCid: PMC1705825

26. Ogden CL, Kuczmarski RJ, Flegal KM, Mei Z, Guo S, Wei R et al. Centers for Disease Control and Prevention 2000 growth charts for the United States: improvements to the 1977 National Center for Health Statistics version. Pediatrics 2002; 109:45-60. http://dx.doi.org/10.1542/peds.109.1.45 PMid: 11773541 